\title{
Data collection methodology for dynamic temperature model testing and corroboration
}

\author{
B. T. Neilson, ${ }^{1 *}$ D. K. Stevens, ${ }^{1}$ S. C. Chapra ${ }^{2}$ and C. Bandaragoda ${ }^{1}$ \\ ${ }^{1}$ Utah Water Research Laboratory, 8200 Old Main Hill, Utah State University, Logan, UT 84322-8200, United States \\ ${ }^{2}$ Civil and Environmental Engineering, 223 Anderson Hall, Tufts University, Medford, MA 02155, United States
}

\begin{abstract}
:
This article describes a data collection approach for determining the significance of individual heat fluxes within streams with an emphasis on testing (i.e. identification of possible missing heat fluxes), development, calibration and corroboration of a dynamic temperature model. The basis for developing this approach was a preliminary temperature modelling effort on the Virgin River in southwestern Utah during a low-flow period that suggested important components of the energy balance might be missing in the original standard surface-flux temperature model. Possible missing heat fluxes were identified as bed conduction, hyporheic exchange, dead zone warming and exchange and poor representation of the amount of solar radiation entering the water column. To identify and estimate the relative importance of the missing components, a comprehensive data collection effort was developed and implemented. In particular, a method for measuring shortwave radiation behaviour in the water column and an in situ method for separating out bed conduction and hyporheic influences were established. The resulting data and subsequent modelling effort indicate that hyporheic and dead zone heat fluxes are important, whereas solar radiation reflection at the water surface was found to be insignificant. Although bed conduction can be significant in certain rivers, it was found to have little effect on the overall heat budget for this section of the Virgin River. Copyright (C) 2009 John Wiley \& Sons, Ltd.
\end{abstract}

KEY WORDS river heat budgets; water temperature; hyporheic; bed conduction; water-sediment exchange; temperature modelling

Received 22 August 2008; Accepted 12 May 2009

\section{INTRODUCTION}

Physically based temperature models provide for the quantification of various heat fluxes as well as aid in understanding how management of river systems affects in-stream temperatures. Most temperature models include surface heat flux terms accounting for net shortwave radiation, longwave radiation, back radiation, sensible heat (conduction/convection) and latent heat (evaporation/condensation). There are, however, additional heat transfer mechanisms that have been identified as potentially important including bed conduction, transient storage (hyporheic exchange/subsurface storage and dead zones/surface storage) and solar radiation penetration and attenuation in the water column. The temperature models found that incorporate a subset of these additional processes are TEMP-84/86 (Beschta and Weatherred, 1984, 1987), Heat Source (Boyd and Kasper, 2003), SNTEMP (Theurer et al., 1984) and River Modelling System (or RQUAL) (Hauser and Schohl, 2003). We were, however, unable to find any one model in the literature that includes the effects of bed conduction, exchange with the hyporheic zone, dead zone interactions and solar radiation penetration and attenuation on main channel temperatures.

\footnotetext{
* Correspondence to: B. T. Neilson, Utah Water Research Laboratory, 8200 Old Main Hill, Utah State University, Logan, UT 84322-8200, United States. E-mail: bethany.neilson@usu.edu
}

Past approaches to understanding specific heat fluxes and their importance in rivers have resulted in conflicting information about the relative flux contributions (Johnson, 2004). The unique characteristics of each system result in differing significant heat fluxes, suggesting that site-specific data are necessary to determine the key factors influencing in-stream temperatures and the appropriate strategies to mitigate heat loads. Several studies have stressed the use of both data and modelling techniques to quantify heat fluxes. The importance of heat conduction between the stream and the bed sediments (bed conduction) was shown to be system dependent and has typically been quantified via modelling and/or data collection (Brown, 1970; Jobson, 1977; Sullivan et al., 1990; Sinokrot and Stefan, 1993; Hondzo and Stefan, 1994; Rutherford et al., 1997; Evans et al., 1998; Meier et al., 2003; Johnson, 2004). Similarly, other sediment-water interactions (hyporheic fluxes) are highly site specific and have been identified using solutes (Bencala and Walters, 1983; Stream Solute Workshop, 1990; Runkel, 1998; Gooseff and Mcglynn, 2005) and heat as tracers (White et al., 1987; Silliman and Booth, 1993; Curry et al., 1995; Curry and Noakes, 1995; Silliman et al., 1995; Constantz et al., 2002; Alexander and Caissie, 2003; Meier et al., 2003; Stonestrom and Constantz, 2003; Hatch et al., 2006; Loheide and Gorelick, 2006).

Although the effects of surface storage in dead zones on main channel in-stream temperatures are not 
often considered, Meier et al. (2003) applied a coupled one-dimensional hydraulics and heat balance dead zone model to estimate the effect of diversions on mountain stream temperatures. In this study, there was no direct discussion regarding the impact of the dead zones on main channel temperatures. Interactions between dead zones and the main channel in the context of solute and waterquality transport, however, have typically been included as part of the concept of transient storage, which is a term used for the combined effect of the hyporheic and dead zone exchanges. This concept and modelling approach has been used in numerous and diverse applications, but original citations include Bencala and Walters (1983) and Runkel (1998). Although transient storage and the associated one-zone modelling (i.e. One-Dimensional Transport with Inflow and Storage (OTIS), Runkel, 1998) are appropriate for understanding the fate and transport of many constituents, the use of a lumped transient storage heatflux term in cases where both dead zones and hyporheic influences are important would be inappropriate due to these two zones being exposed to different heat transfer processes.

The reflection, penetration and absorption of radiation in water bodies have been studied primarily in lakes and oceans (Austin and Halikas, 1976; Jerlov, 1976; Kirk, 1994; Sweeny et al., 2005). The limited information about shortwave radiation behaviour, as opposed to photosynthetically active radiation or other portions of the spectral range, in freshwater systems includes work by Sellers (1965); Dale and Gillespie (1977); Kirk (1994); Wang and Seyed-Yagoobi (1994); Evans et al. (1998) and Johnson (2004). Because shortwave radiation is a dominant heat flux in most systems, it was determined that data regarding the reflection of shortwave radiation above and transmission within the water column would be key in quantifying the significance of this flux.

Based on past efforts to understand these heat fluxes, the three key objectives of the current study were (1) to determine the data collection strategies necessary to identify the important energy balance components not represented in standard surface-flux temperature models, (2) to identify key data types and (3) to determine how these data can assist in further model development, testing and calibration. This article presents the key data collected and the utility of each data type in understanding important heat fluxes, qualitative conclusions drawn from the data and selected modelling results that assist in confirming data observations.

\section{STUDY AREA}

Temperatures in the Virgin River, Utah, have been a topic of intense study due to concerns over habitat loss of unique native fishes including two endangered fish species: Virgin River Chub (Gila seminuda) and woundfin (Plagopterus argentissimus). The section of the Virgin River between Hurricane and Washington, near St. George, chosen for the study (Figure 1) experiences

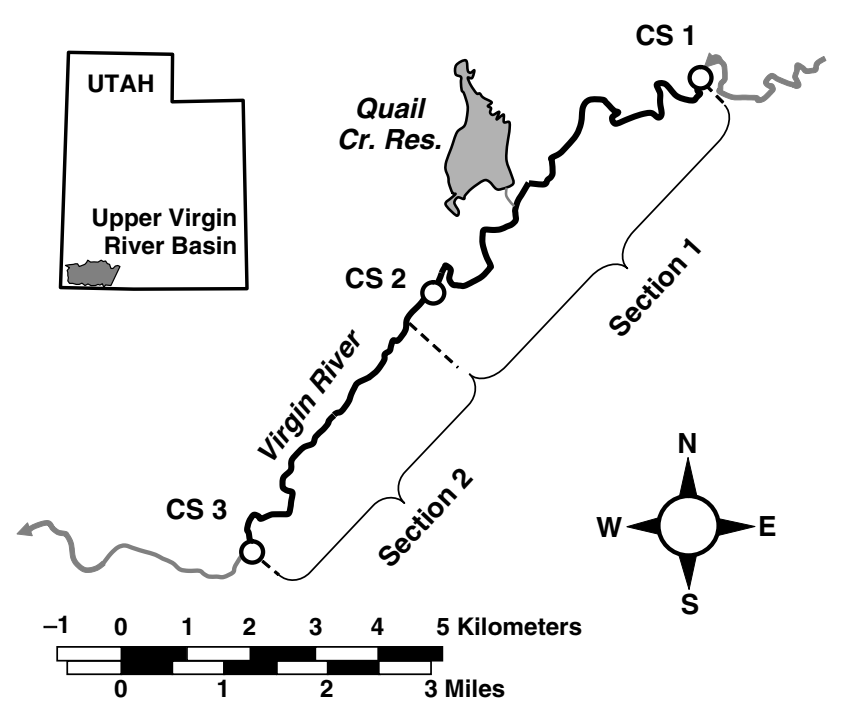

Figure 1. Layout of Upper Virgin hydrologic cataloging unit. The portion of the river studied is highlighted

extremely hot and dry summers with maximum daily air temperatures consistently greater than $38^{\circ} \mathrm{C}$ for the majority of July and August. Of greatest concern is the low-flow summer season when elevated stream temperatures limit fish habitat. Large amounts of temperature, flow and turbidity data have been collected by a variety of agencies in this portion of the Virgin River to understand how best to meet the water demands of a rapidly growing urban population along with agricultural and fish habitat requirements. These data, however, were not expressly collected for the purpose of quantifying or investigating energy fluxes in the river. Consequently, managing the river flows to mitigate in-stream temperature extremes has been hampered by incomplete understanding of the river's dominant heat fluxes.

Figure 1 shows the study reach and data collection points. There are a number of inflows along the reach, however, the return flow from Quail Creek Reservoir is the largest and significantly influences in-stream temperatures. Cross-section 1 (CS 1), the upper boundary of the study reach, was located at a transition between a pool and a run after a large horseshoe bend in the river. The substrate at CS 1 consists of compacted gravel and cobble, filled with sand. Hurricane Bridge (CS 2) is situated near the middle of the study reach, $11 \mathrm{~km}$ below CS 1, between two riffles near the tail of a small pool. The substrate at CS 2 consists of loose and mobile sand. The terminus of the study reach, CS $3(18 \mathrm{~km}$ below CS 1), was located above the backwater of the Washington Fields Diversion structure in a long run consisting of loose and mobile sand.

This section of the Virgin River was selected because it has minimal groundwater influence (Herbert, 1995). The reach was split into two sections on the basis of bed slope and the substrate distribution established from a previous mapping effort. Section 1, including the reaches between CS 1 and a portion of the river $1.75 \mathrm{~km}$ below CS 2, has an average bottom slope of 0.0039 and bed substrate consisting of sand (56\%), gravel $(26 \%)$ and 
cobble (14\%). Section 2 has an average slope of 0.0012 and bed substrate primarily consisting of sand $(72 \%)$, gravel $(15 \%)$ and cobble (10\%) and therefore, has the potential to behave differently in terms of hyporheic influences and bed conduction than the upper section. Bottom sediments are highly mobile in this lower section.

Temperature dynamics in many rivers are dominated by surface fluxes and can, therefore, usually be modelled by only accounting for these fluxes. In the case of the Virgin River, however, preliminary work found that a standard temperature model that included only advection and surface flux terms was not sufficient to capture the nuances of the temperature dynamics (Addley et al., 2005). Due to several site-specific features of the Virgin River system (e.g. unconsolidated and mobile lightcoloured sediments, very high summer air temperatures and rapid fluctuations between clear and turbid water due to storm events) and fluxes identified by others to be important in quantifying in-stream temperatures, we hypothesized that the model could be improved by including energy flux terms for bed conduction, exchange between the main channel and hyporheic zone, dead zone exchange, substrate warming by solar radiation penetration and a more appropriate representation of solar radiation entering the water column. Although in many systems vegetative and topographic shading can influence in-stream temperatures, these influences were found to be unimportant in this study reach.

\section{METHODS}

Webb and Zhang (1997) state that despite the importance of understanding heat sources and sinks in river systems for predicting water temperatures, few studies have collected in situ measurements of all energy balance components. In this study, we collected such data to understand the contributions of the different energy balance components that may affect model performance. In addition to each of these types of data, other data (e.g. tracer studies, weather data, inflow discharge and temperatures, etc.) were collected to test, populate and parameterize the resulting temperature model. Only portions of the data relevant to understanding energy balance fluxes are presented here, however, a description of all the data collected and the model development is presented in Neilson (2006).

The original temperature model developed and implemented in the preliminary study that included only surface fluxes was based on equations for atmospheric longwave radiation $(5-25 \mu \mathrm{m})\left(J_{a n}\right)$, water longwave radiation $\left(J_{b r}\right)$, conduction and convection $\left(J_{c}\right)$ and evaporation and condensation $\left(J_{e}\right)$ from Chapra (1997). In contrast, the shortwave radiation term $(0 \cdot 31-2 \cdot 8 \mu \mathrm{m})\left(J_{s n}\right)$ was populated directly from a time series of field pyranometer measurements. As mentioned previously, this modelling effort demonstrated that the surface flux-only approach could not explain temperature behaviour in the Virgin River, particularly at CS 3. This led to the development of the Two-Zone Temperature and Solute (TZTS) model of Neilson (2006). Figure 2 shows the heat fluxes that are accounted for in the TZTS model. Bed conduction, exchange with the hyporheic zone and dead zone exchange fluxes were incorporated into the model to be used in tandem with the data collected to assist in determining the significance of each flux. In this model, exchange with the hyporheic and dead zones is approximated using one-dimensional mass transfer process across the interfacial area with the main channel.

The data collection portion of the study was implemented in two stages. The first stage was carried out in July 2005 and focused on determining if the data collected represented the fluxes of interest. The second stage was modified based on the first effort and occurred

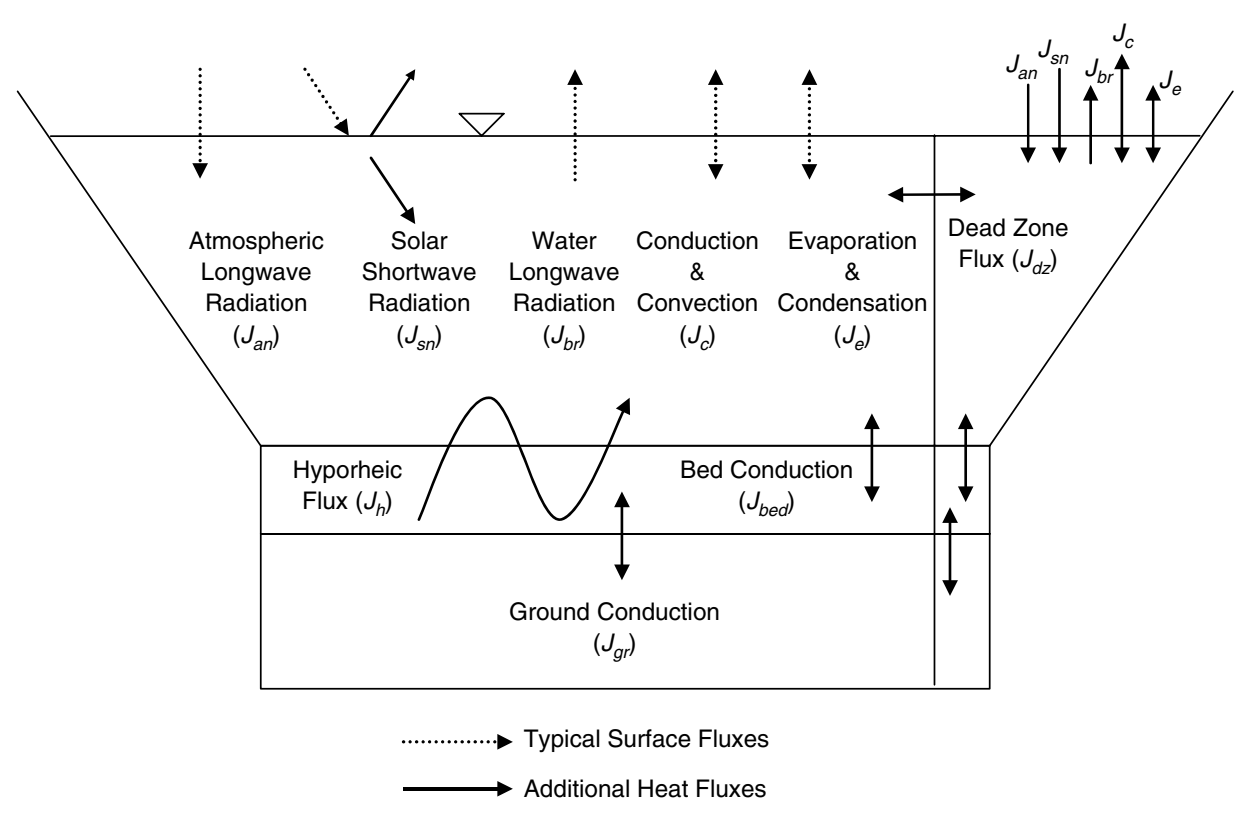

Figure 2. Components of the energy balance included within the two-zone temperature and solute model 
in September 2005. Locations CS 1, CS 2 and CS 3 (Figure 1) were selected as data collection sites for both efforts to represent the bed slope and substrate conditions in the two study sections. Hobo Water Temp Pro V1 (Onset Corporation, Bourne, MA) temperature probes were placed in the water column and in the sediments to measure temperature at 5-min intervals at each location. Figure 3 shows the details of the probe placement in each cross-section. Probes 1 and 3 were situated to measure the temperatures of the dead zones. Probe 2 measured the main channel temperatures. Probe 4 was placed on the surface of the bed to measure the temperature of the water at or near the sediment-water interface and potentially measure the effects of substrate warming due to solar radiation penetration. Based on Silliman and Booth (1993), probes 5-7 were buried at approximately 3, 9 and $20 \mathrm{~cm}$ to determine the depths at which sediment interacted with the water column and provide an understanding of bed conduction and other possible heat sinks or sources in the sediments (e.g. solar radiation effects and hyporheic influences).

Results from the initial data collection effort led to the hypothesis that hyporheic flow may have influenced temperatures measured in the substrate at CS 2 and 3. In September, three more probes (8-10) were buried at each site in the substrate and were isolated from lateral hyporheic advection by a plastic cylinder open at both ends $(\sim 30 \mathrm{~cm}$ diameter and $30 \mathrm{~cm}$ tall) that was installed flush with the bed (Figure 3 ). The cylinders were installed by shimmying them into the sand and then back-filling when necessary. These probes $(8-10)$ were placed to provide independent measures of vertical heat transfer, which was initially assumed to primarily be due to bed conduction.

During the day, exposed slow-moving dead zones along the channel edge may exhibit higher temperatures than the main channel because of their shallow depth and reduced exchange with the main channel. Additionally, since these areas are shallower than the main channel, more solar radiation may penetrate to and warm the substrate. A number of such zones were identified in the study reach during preliminary surveys and tracer studies at the measurement sites CS 1-3. The dynamics of energy exchange between the main channel and these dead zones were characterized by measuring the difference in temperatures in this zone versus the main channel by the placement of probes 1 and 3 (Figure 3). Dead zone measurements were made on the northwest and southeast banks at each of the cross-section locations.

Probes 1-3 (Figure 3) were anchored in the water column with rebar at approximately mid-depth of the water column. Sediment probes 5-7 and 8-10 were attached to a long piece of $1.27-\mathrm{cm}$ PVC pipe that would slide over the rebar anchored in the centre of the cross-section. Three probes were attached externally at the specified depths. A short PVC arm indicated where the substrate surface should be located. In this application, probes were buried in the substrate by a combination of pounding and substrate removal and replacement. It was recognized that it is possible to alter the local permeability and create hyporheic exchange when excavating substrate to bury equipment. However, at each location in this study, the bed substrate (specifically the top 5-10 cm) primarily consisted of unconsolidated sand and therefore, the probability of altering the permeability was decreased. Due to the constant movement of sand, the depths of the sediment probes at CS 2 and CS 3 varied by $\pm 2 \mathrm{~cm}$. Consequently, the burial depths of the sediment temperature probes were monitored and adjusted by removing or replacing sand to match the PVC arm to maintain the designed depths.

Data regarding incoming shortwave solar radiation, water surface albedo and shortwave radiation penetration through the water column to the substrate and its reflection from the substrate were collected using two CM3 pyranometers (Kipp and Zonen, Bohemia, NY). These pyranometers were mounted to a plate with one facing up and one facing down (creating an albedometer) to measure the incoming and reflected shortwave radiation. Hourly measurements of incoming and reflected shortwave radiation were collected just above the water surface, in the mid portion of the water column and just above the bed surface. Additionally, shortwave radiation attenuation was determined using the measures of shortwave radiation at different depths in the water column and were taken during each study several times daily to understand how the attenuation changes with solar azimuth and other variable conditions (e.g. turbidity).

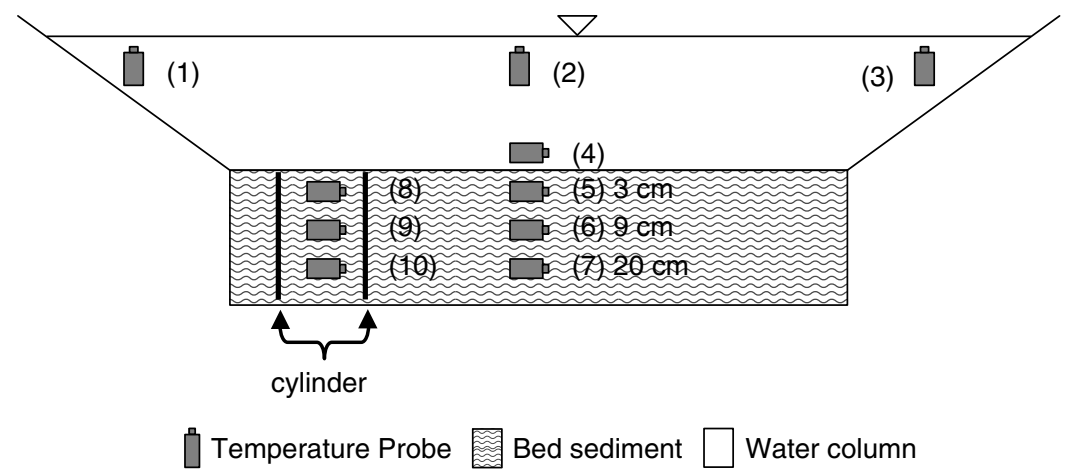

Figure 3. Locations of temperature probes at each of the three locations within the study reach 


\section{FIELD RESULTS AND DISCUSSION}

\section{Bed sediment temperatures}

Loheide and Gorelick (2006) state that similar to conduction, hyporheic exchange produces suppressed maxima, increased minima and induces time lags in water column temperatures. Data resulting from probes 5-10 (Figure 3) can assist in determining whether hyporheic exchange or bed conduction is dominant at each location.

Figure 4 shows the September study results of the buried temperature probes at CS 1 . The sediment temperatures have a smaller magnitude and are lagged relative to the main channel temperatures. Such behaviour is typical of sediments dominated by heat conduction. The results from the buried probes (5-7) at CS 2 and CS 3 for the September study (Figure 5) exhibit larger attenuation and time lags than CS 1. This suggests that additional heat transfer mechanisms (e.g. hyporheic exchange) may

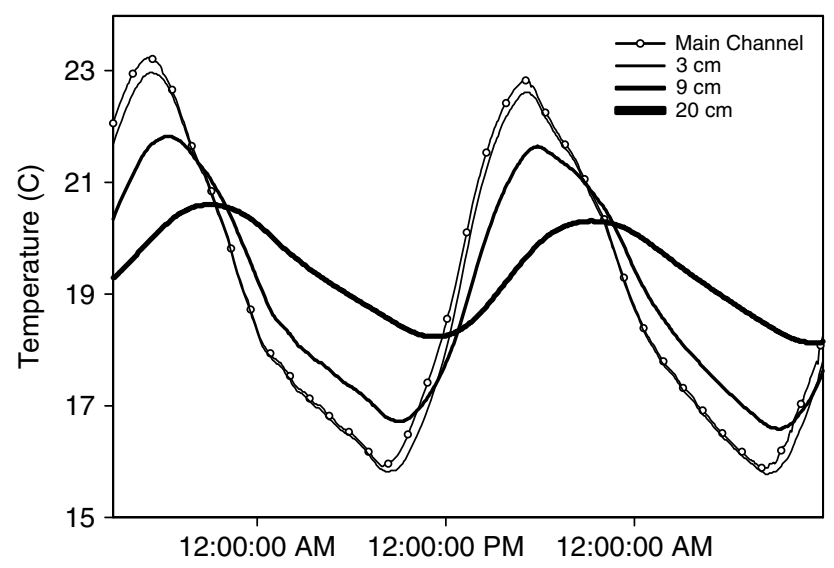

Figure 4. Cross-section 1 (CS 1) temperature probes buried at 3, 9 and $20 \mathrm{~cm}$ in the river sediments in the end of September 2005 be present. These data are consistent with others that have observed hyporheic exchange resulting in sediment temperatures with smaller magnitudes and time lags from the main channel temperatures (Silliman and Booth, 1993; Silliman et al., 1995; Evans and Petts, 1997; Hatch et al., 2006; Arrigoni et al., 2008). Beyond the time lag and buffering, CS 2 and 3 additionally have a much more irregular temporal variability that was tentatively attributed to changes in bed substrate movement. These large high-frequency temperature fluctuations are exhibited at the intermediate depths $(3$ and $9 \mathrm{~cm}$ ) at CS 2 and CS 3. Because the water temperature time series does not manifest such variability, this suggests that hyporheic flows are influencing the probes at these depths. This hypothesis is in part supported by the fact that the deepest probes $(20 \mathrm{~cm})$ are also smooth which may indicate that the hyporheic intrusions do not penetrate below a certain depth and that conduction becomes dominant somewhere between 9 and $20 \mathrm{~cm}$. As a consequence, the signal is further dampened between 9 and $20 \mathrm{~cm}$.

The bed substrate at CS 1 consisted of gravel and cobble tightly compacted with sand. Additionally, it was located in a low-velocity portion of the channel occurring after the river strikes a canyon wall, creating a horseshoe bend in the river. At this location, downward exchange between the main channel and the hyporheic zone was less likely. Field observations of cool, porous and loose sand below the surface at CS 2 and 3 suggested that the influence of the hyporheic zone was greater at these lower two cross-sections.

Sediment temperatures in rivers and streams typically change with depth due to conduction forced by diel fluctuations of the overlying water column. In the situation where strong downwelling from the water column into the
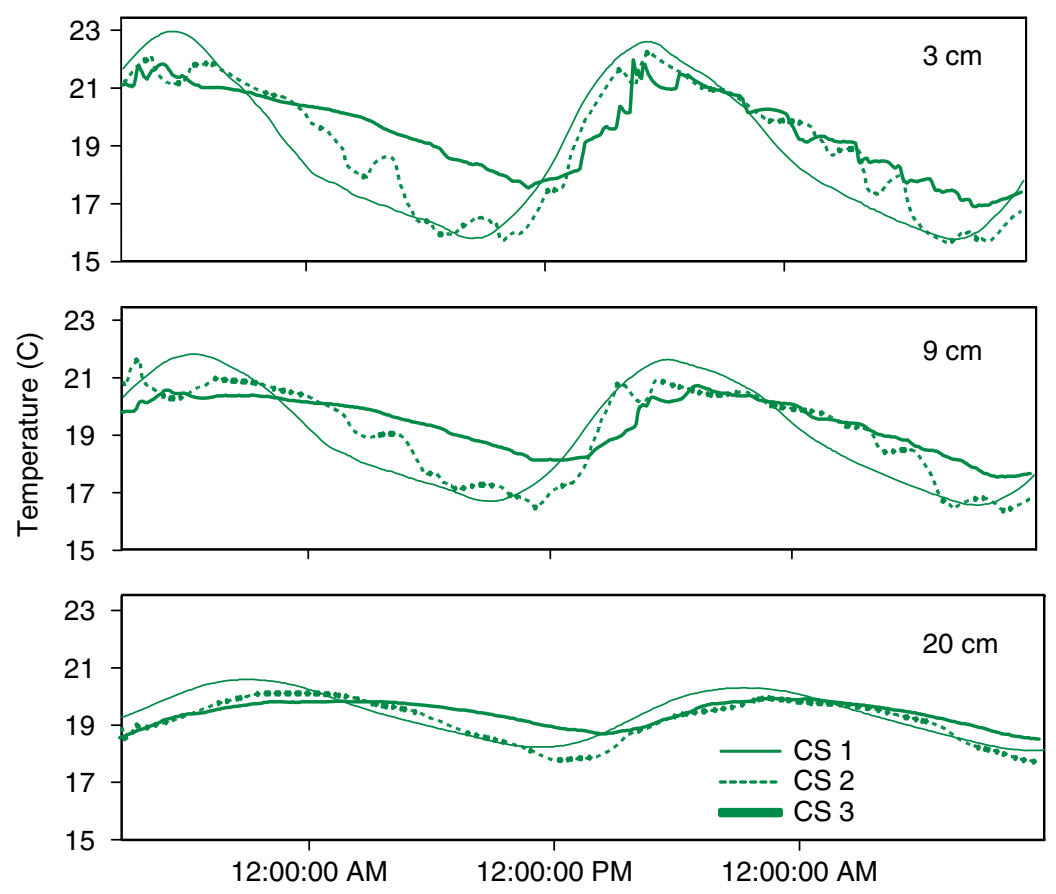

Figure 5. Sediment temperature probe results at depth of 3, 9 and $20 \mathrm{~cm}$ for cross-sections $1-3$, September 2005 study 
hyporheic zone is occurring, advection is dominant over conduction, and sediment temperatures may mimic instream temperatures closely. In situations when advection through the hyporheic zone is insignificant due to low permeability, bed conduction can be the prevailing heat flux in the sediments (Cardenas and Wilson, 2007). To further attempt to separate out the confounding influences of conduction and advection through the bed sediments, data collected within the cylinder (probes $8-10$ ) can be compared with those with no shielding (probes 5-7).

Figures 6 through 8 show the results from the two sets of buried probes by location for the September study. Figure 6 indicates that at CS 1, the temperatures inside and outside of the cylinder were very similar and did not exhibit the high-frequency temperature variations, providing little evidence of exchange with the hyporheic zone. In contrast, the two sets of sediment probes at CS 2 and CS 3 show significant differences (Figures 7 and 8 ). Note that while the temperatures inside the cylinder are smooth at CS 2, similar to CS 1, the temperatures in the cylinder at CS 3 for the 3- and 9-cm probes showed variations comparable to those outside the cylinder. The fluctuations in the cylinder suggest the influences of vertical advective heat exchange and therefore, show that the open cylinders will not measure the influences of only conduction under some circumstances (i.e. areas of upwelling or downwelling). Some of the large changes in temperature in a small amount of time in the afternoon at CS 3 may be due to manual removal of sediment that had deposited at the location of the equipment.

Another interesting feature of the data at CS 2 (Figure 7) is that the temperatures in the cylinder are higher than those outside the cylinder. It is assumed that the probes in the cylinder are experiencing primarily vertical advective influences and conduction. The probes outside the cylinder are being exposed to conduction, horizontal advective influences and vertical advective influences. Since horizontal flow can affect the vertical temperature distribution in groundwater ( $\mathrm{Lu}$ and $\mathrm{Ge}, 1996$ ), it is hypothesized that the lower temperatures outside the cylinder are due to the effects of horizontal flow through the substrate causing a dampening effect.

Table I shows the average of the absolute value of the differences and the maximum of the absolute value of the differences at each depth. The maximum differences are greatest in CS 2 and 3 with the largest difference being about $2^{\circ} \mathrm{C}$ at both CS 3 at $3 \mathrm{~cm}$ and CS 2 at $20 \mathrm{~cm}$. These high values are explained by that fact that the bed substrate at CS 3 was quite loose and mobile, resulting in increased velocities in the substrate and shorter residence times, and that CS 2 was located near the tail of pool situated between two riffles where water may be plunging into the deeper substrate. The average differences are greatest at CS 2 at 9 and $20 \mathrm{~cm}, 0.59^{\circ} \mathrm{C}$ and $0.77^{\circ} \mathrm{C}$, respectively. In Figure 7, however, the large absolute differences are primarily due to the time lag in the two sets of curves. At CS 3, the differences are more uniformly offset and the lag is not present.

These data suggest that hyporheic flow affects this system by changing bed temperatures and the magnitude of the effects would be related to the rate of exchange and dominant flow path lengths through the hyporheic zone. According to these data, the amount of advective exchange in the sediments in the lower portion of this system (CS 2 and 3) appears to be higher than in the upper portion (CS 1) at these limited sampling locations.
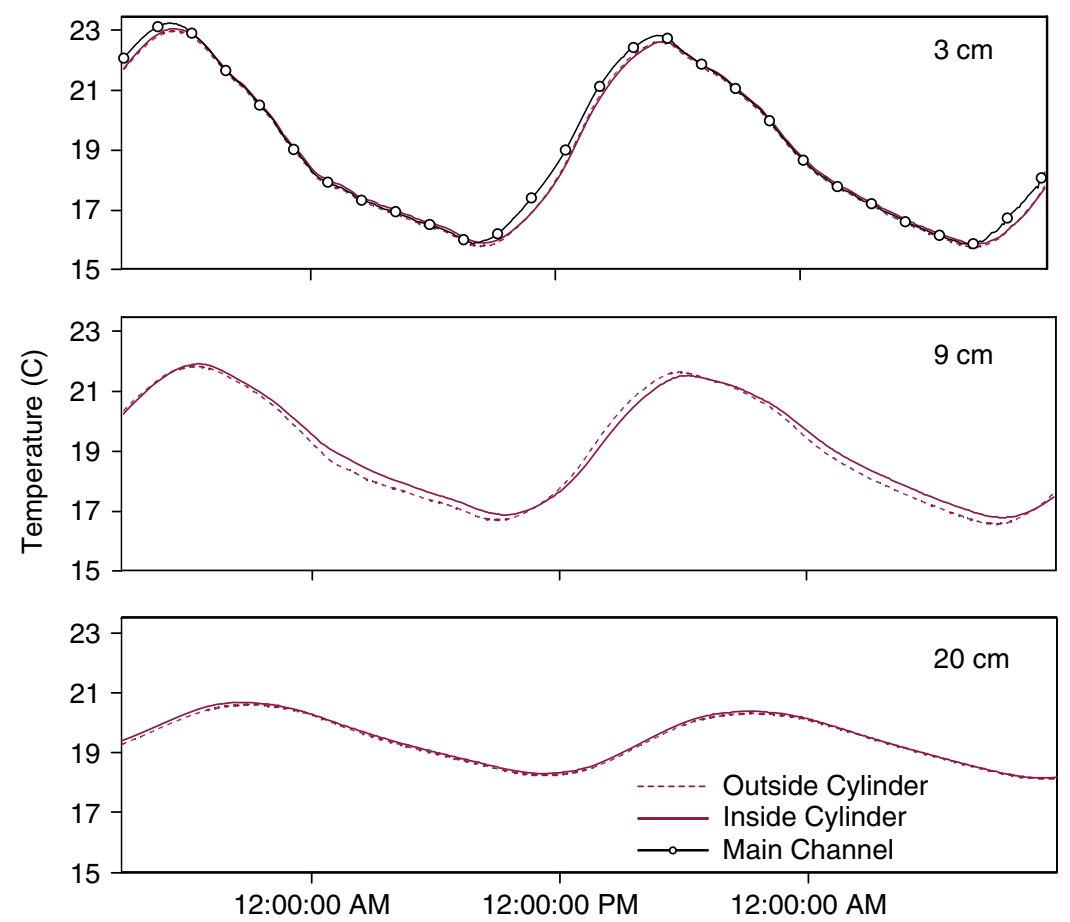

Figure 6. Cross-section 1 sediment probes buried at 3,9 and $20 \mathrm{~cm}$ showing the effects of conduction and other vertical heat exchange (inside cylinder) and hyporheic flow + conduction (outside cylinder) in September 2005 

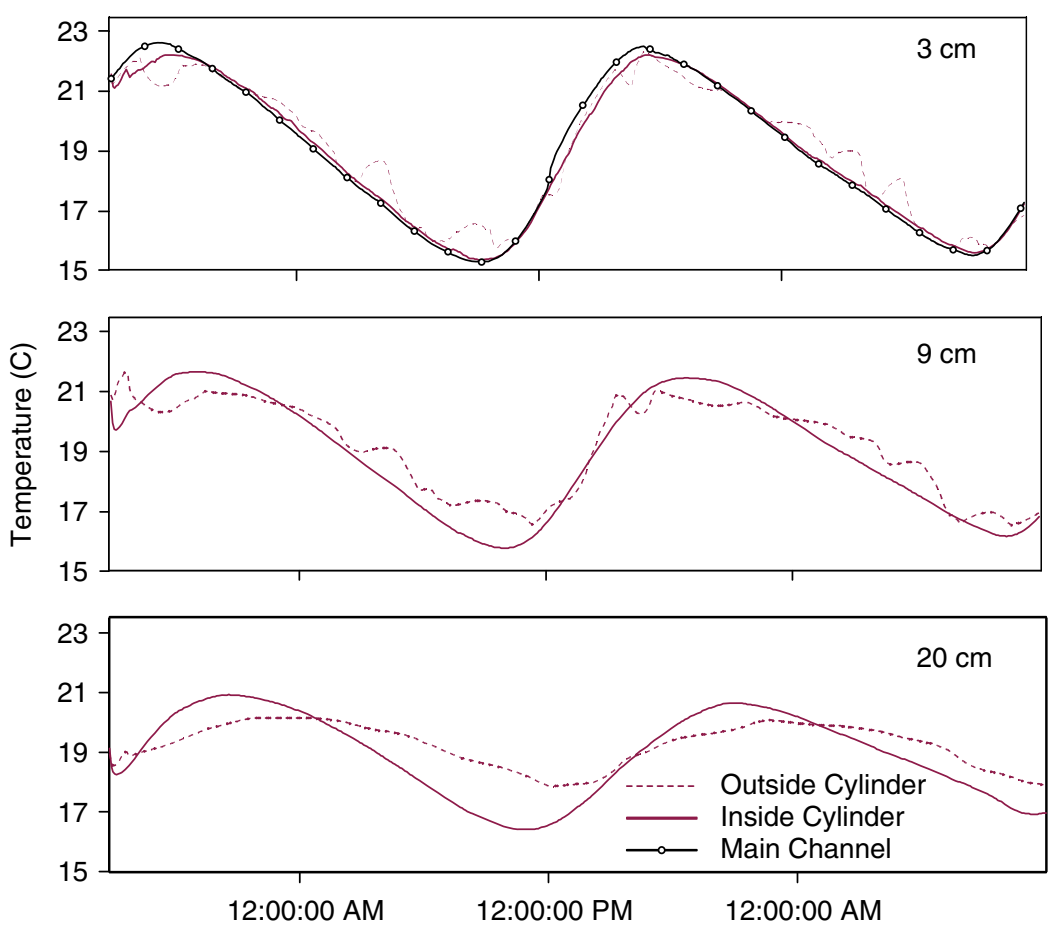

Figure 7. Cross-section 2 sediment probes buried at 3,9 and $20 \mathrm{~cm}$ showing the effects of conduction and other vertical heat exchange (inside cylinder) and hyporheic flow + conduction (outside cylinder) in September 2005
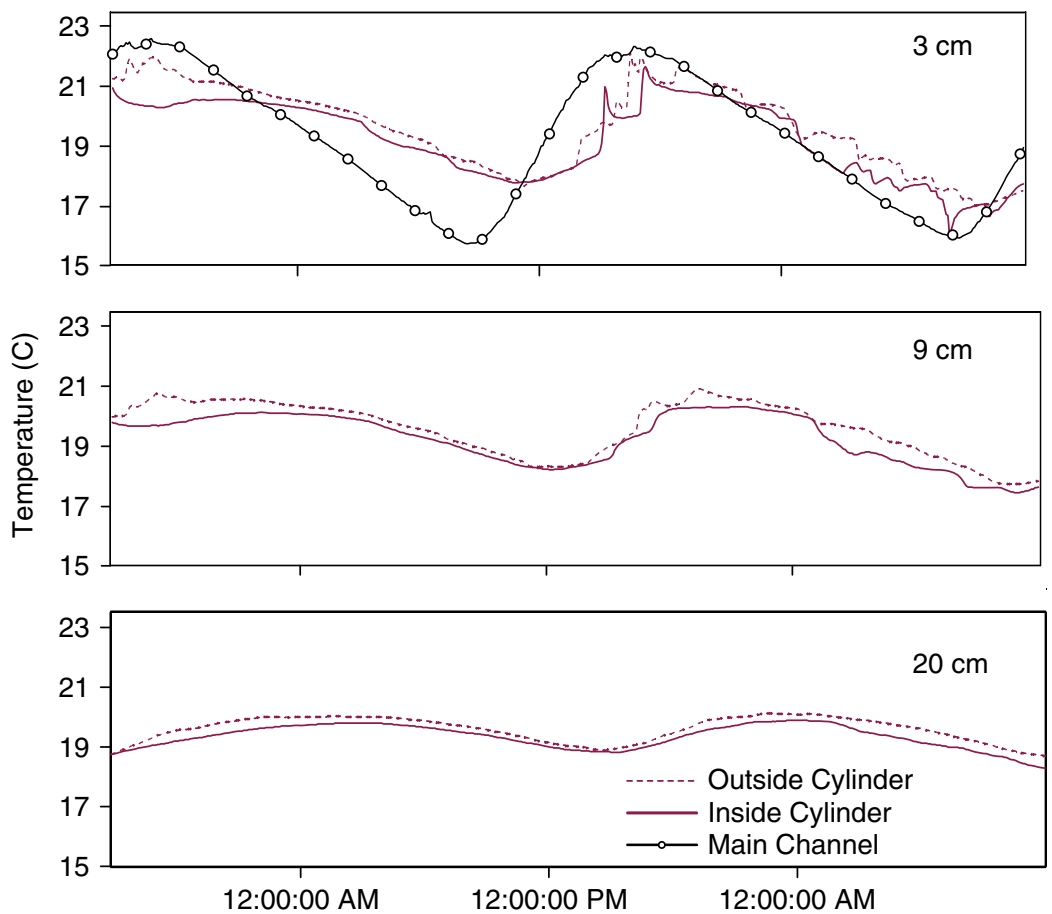

Figure 8. Cross-section 3 sediment probes buried at 3,9 and $20 \mathrm{~cm}$ showing the effects of conduction and other vertical heat exchange (inside cylinder) and hyporheic flow + conduction (outside cylinder) in September 2005

Table I. Comparison of conduction probes versus hyporheic/conduction at each depth and location

\begin{tabular}{|c|c|c|c|c|c|c|}
\hline \multirow[t]{2}{*}{ Cross-section } & \multicolumn{2}{|c|}{$3 \mathrm{~cm}$} & \multicolumn{2}{|c|}{$9 \mathrm{~cm}$} & \multicolumn{2}{|c|}{$20 \mathrm{~cm}$} \\
\hline & Ave|Diff $\mid\left({ }^{\circ} \mathrm{C}\right)$ & $|\mathrm{Max}|\left({ }^{\circ} \mathrm{C}\right)$ & Ave $|\operatorname{Diff}|\left({ }^{\circ} \mathrm{C}\right)$ & $|\operatorname{Max}|\left({ }^{\circ} \mathrm{C}\right)$ & Ave $|\operatorname{Diff}|\left({ }^{\circ} \mathrm{C}\right)$ & $|\operatorname{Max}|\left({ }^{\circ} \mathrm{C}\right)$ \\
\hline CS 1 & 0.01 & $0 \cdot 17$ & $0 \cdot 19$ & 0.40 & 0.06 & $0 \cdot 14$ \\
\hline CS 2 & $0 \cdot 35$ & $1 \cdot 3$ & 0.59 & $1 \cdot 6$ & 0.77 & $2 \cdot 0$ \\
\hline CS 3 & 0.44 & $2 \cdot 1$ & $0 \cdot 35$ & $1 \cdot 1$ & $0 \cdot 25$ & 0.48 \\
\hline
\end{tabular}

Note: CS, cross-section. 


\section{Dead zone temperatures}

Figures 9 and 10 show the temperatures for both the dead zone and main channel probes at each cross-section for July and September. The temperatures in the main channel and the dead zones are similar except during the warming period at CS 3. The differences between these temperatures were greatest in July when the air temperatures were the highest and exposure to solar radiation

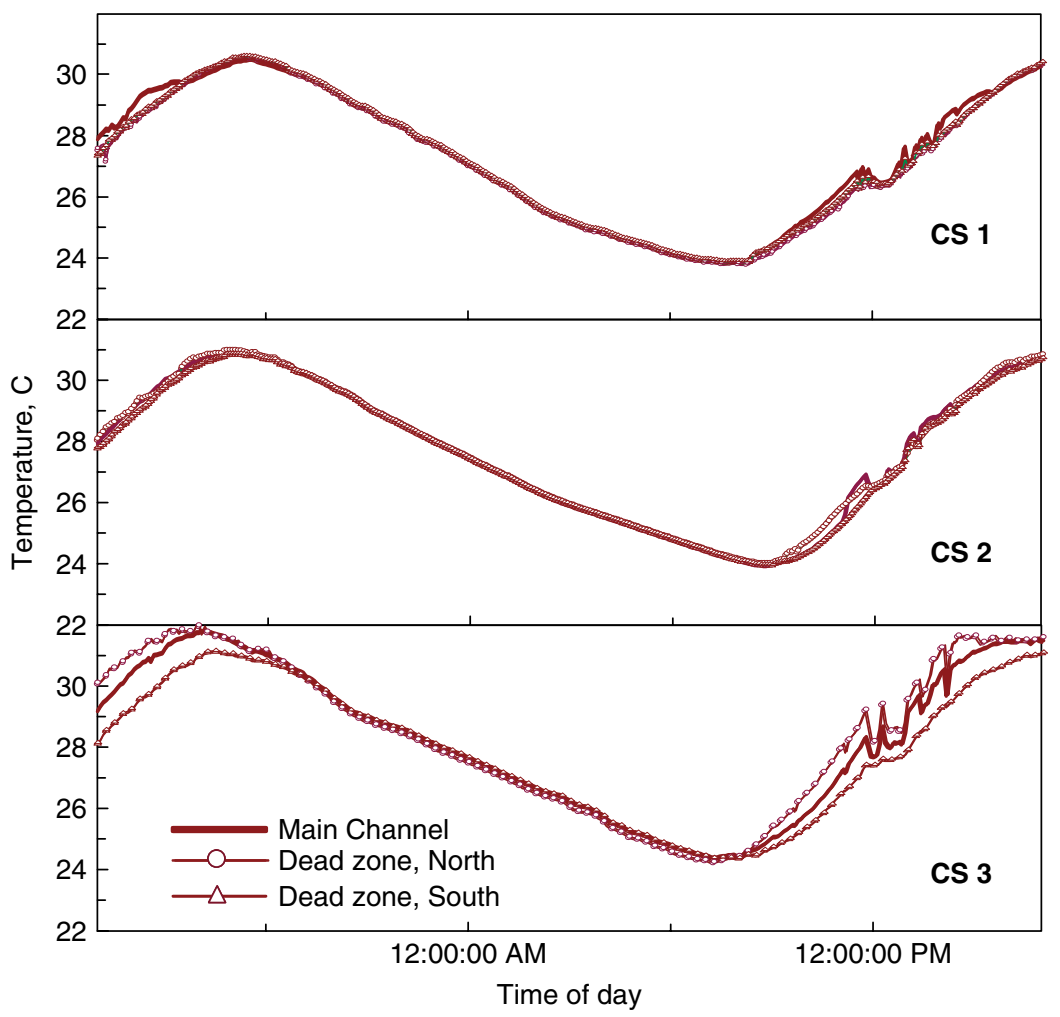

Figure 9. Dead zone temperatures in the north edge of water and south edge of water for cross-sections 1-3 in July 2005

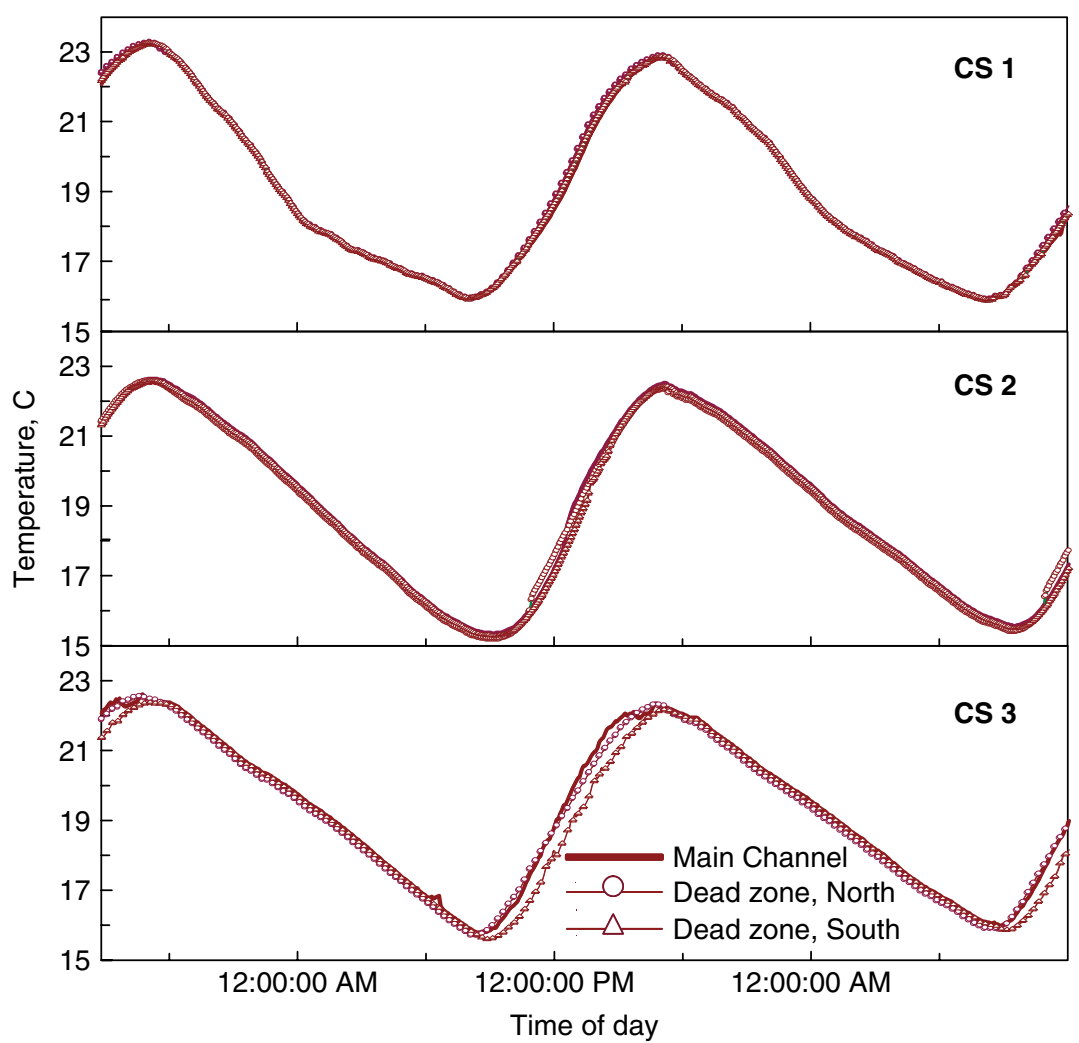

Figure 10. Dead zone temperatures in the north edge of water and south edge of water for cross-sections 1-3 in September 2005 
was the greatest (e.g. exposed CS 3 dead zone, North in Figure 9).

The differences between the two dead zones and the main channel in CS 1 and 2 are near measurement error $\left( \pm 0.2^{\circ} \mathrm{C}\right)$ for most of the study. Contrary to the initial hypothesis about dead zones being a heat source during the day, the dead zone probe temperatures (Figures 9 and 10) are often slightly cooler than the main channel between mid-morning and early evening. The differences in CS 3 in July (Figure 9), however, are greater than at CS 1 and 2, and differ between the north and south edges of the river cross-section. At CS 3, during this study time period, the south edge of water was shaded during the hottest portion of the day. The north edge of water was exposed to the sun all day and shallow resulting in faster heating than the main channel, however, these temperatures eventually converge and reach approximately the same peak temperature. The shaded south-edge probe did not reach this same maximum temperature. This implies that although shade along the banks of a wide river may not significantly change the overall main channel temperatures, it can affect the shallow areas near the bank and create refugia for fish during the hottest times of the summer.

\section{Shortwave radiation behaviour}

In three separate solar radiation studies in June, July and September 2005 (the latter two being part of the study discussed in this article) with turbidities ranging from approximately 2 to 440 NTU and water depths from 51 to $84 \mathrm{~cm}$, we found that (1) less than $10 \%$ of incoming shortwave radiation is reflected from the water surface, (2) high turbidity increased reflection by $3-7 \%$ relative to clear water and (3) the amount of solar radiation reaching the substrate may be sufficient to warm the substrate at the shallower depths (Neilson, 2006). Figure 11 shows the data resulting from the pyranometer measurements during one day of the September study. The lines with circle symbols present the incoming and reflected radiation off the water surface for this day and show that a small percentage of radiation is reflected during the bulk of the day. The lines with the triangle symbols show that incoming radiation absorbed by substrate was significantly greater than that reflected from the substrate, suggesting that a warming of the substrate surface could be occurring.

Figure 12 compares temperatures of the main channel temperature probe at mid-depth in the water column, a probe resting on top of the substrate and the probe (outside the cylinder) placed $3 \mathrm{~cm}$ into the substrate. These plots show that the top layer of the substrate either mimics the main channel temperatures, the substrate below or a combination of both. They also are slightly cooler during the daily peak than the main channel temperatures. Because the probe sitting at the substrate/water interface does not exhibit a temperature increase, it is hypothesized that a combination of advection across this surface, conduction with the water column, deeper ground conduction and exchange with the hyporheic zone may be muting the effects of the solar radiation on the substrate.

\section{MODEL RESULTS}

Initial qualitative data analyses provided information regarding the potential importance of each heat flux. The relative contributions of these fluxes were determined with the TZTS model (Neilson, 2006) that used main channel, dead zone and bed sediment temperature data for calibration and corroboration. For the July study period, main channel temperature information from CS 1 was applied as a boundary condition. Since the sediment

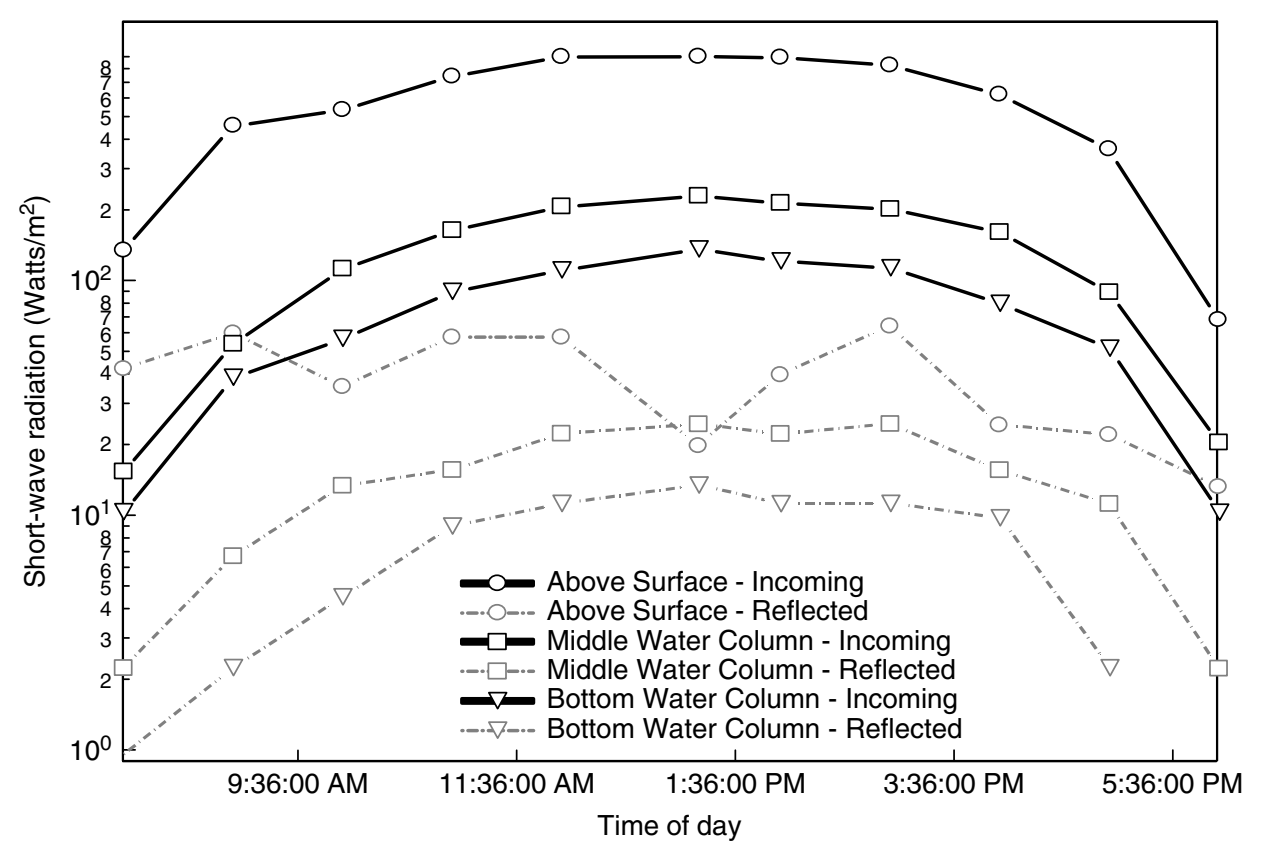

Figure 11. Pyranometer readings during slightly turbid conditions (September 2005) 


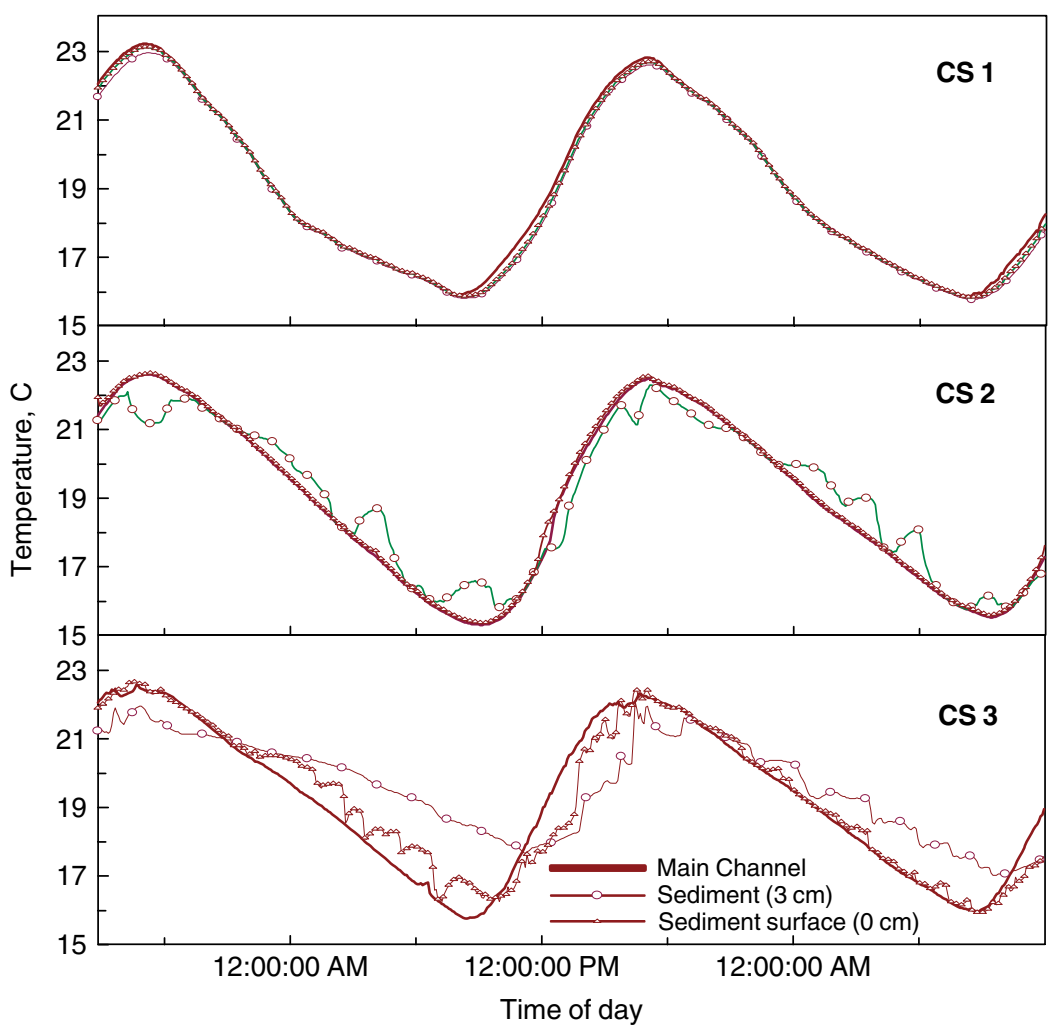

Figure 12. Comparison of temperatures for the main channel, bottom sediment and $3 \mathrm{~cm}$ below the bottom substrate in September 2005

thermal properties must be independently determined to use heat as a means to quantify advective fluxes or hyporheic exchange (Stonestrom and Constantz, 2003; Hatch et al., 2006), data collected from probes 8-10 at CS 1 and 2 were used to determine an average thermal diffusivity of the sediments using inverse modelling.

As described more thoroughly in Neilson (2006), the other model parameters were calibrated using temperature data from the main channel at CS 2 and CS 3 by employing the Multiobjective Shuffled Complex Evolution Metropolis (Vrugt et al., 2003) algorithm to determine the range of parameters resulting in objectively similar predictions. Of these parameter sets, the one resulting in the best fit at both locations, CS 2 and CS 3, was selected. Other temperature data sets (i.e. probes 1, 3 and 5-7) at CS 2 and CS 3 were used as corroboration data. Similar calibration efforts were conducted using solute data alone and solute and temperature data combined. The results presented in this article are from the calibration effort based solely on main channel temperature data at CS 2 and CS 3.

Heat fluxes resulting from the modelling effort show the individual effects of some of these identified heat sources and sinks. The initial modelling results do not include solar radiation penetration of the water column or reflection of solar radiation from the water surface throughout the day. However, dead zone surface fluxes and exchange with the main channel, advection into and out of the hyporheic zone and bed conduction were included. The individual fluxes calculated using this model over one day are shown in Figures 13 and
14. Note that the surface flux values are the sum of the evaporation and condensation $\left(J_{e}\right)$, conduction and convection $\left(J_{c}\right)$, water longwave radiation $\left(J_{b r}\right)$ and atmospheric longwave radiation $\left(J_{a n}\right)$ terms. The shortwave radiation term was left separate in the plot due to its magnitude and importance.

Figures 13 and 14 indicate that the dominant heat flux into the system is shortwave solar radiation (measured at CS 1). The other combined surface flux terms create a net loss of heat from the system. Confirming the observations from some of the dead zone temperature probes, the dead zone flux provides a heat source during the night and a sink during the day. While on average this may be true, the dead zone temperature measurements shown in Figures 9 and 10 are both higher and lower than the main channel depending on exposure, aspect and depth of the measured dead zone. Regardless, the dead zone data and resulting modelling fluxes emphasize the importance of separating out the surface and subsurface storage zones associated with transient storage. Additionally, this stresses how stream morphology affects the in-stream temperatures and ultimately aquatic species. If dead zone areas are lost (e.g. through stream channelization), the energy buffering capacity associated with the dead zones may also be lost.

The two sediment fluxes, bed conduction and advective exchange with the hyporheic zone, prove to contribute to the lags in the in-stream diurnal temperature fluctuations. Bed conduction is the smaller of the two sediment fluxes, but it does result in a heat sink at night and a source during the afternoon hours in Section 1. Model results 


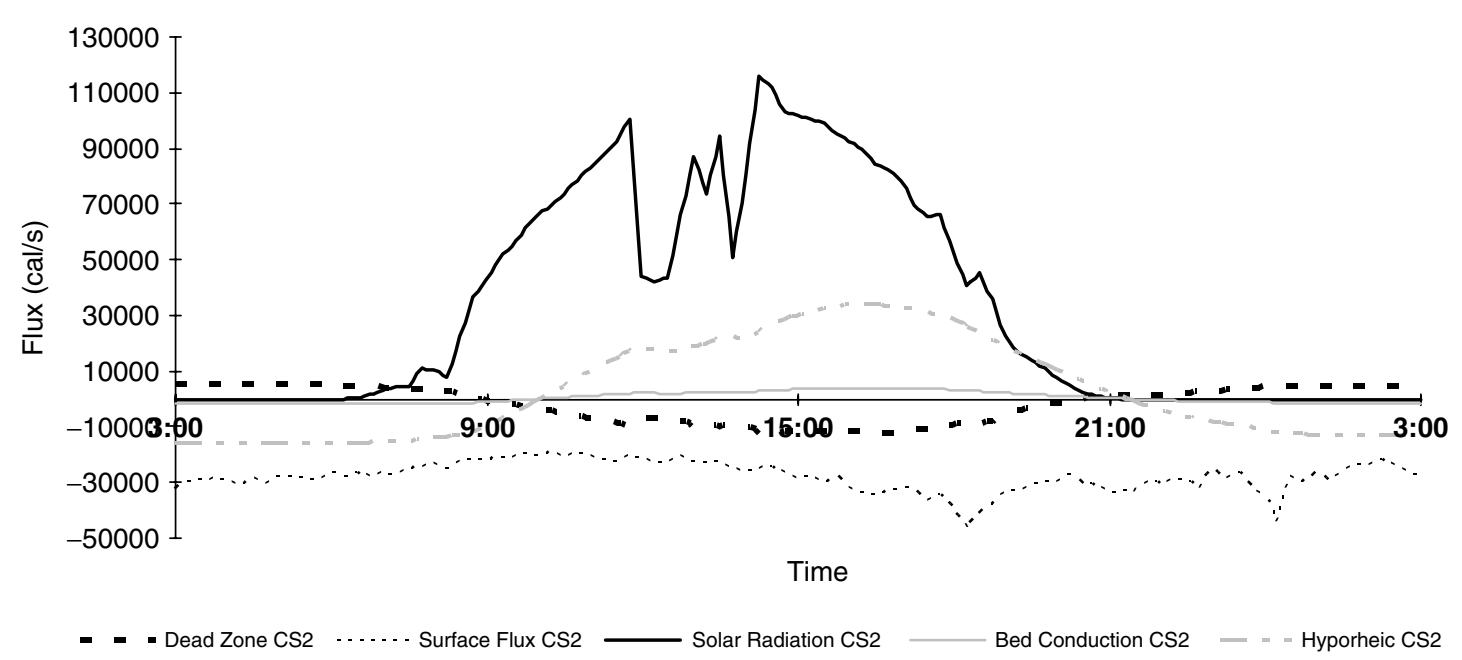

Figure 13. Heat balance at cross-section 2 over one day ( 3 a.m.-3 a.m.) in the main channel of the river

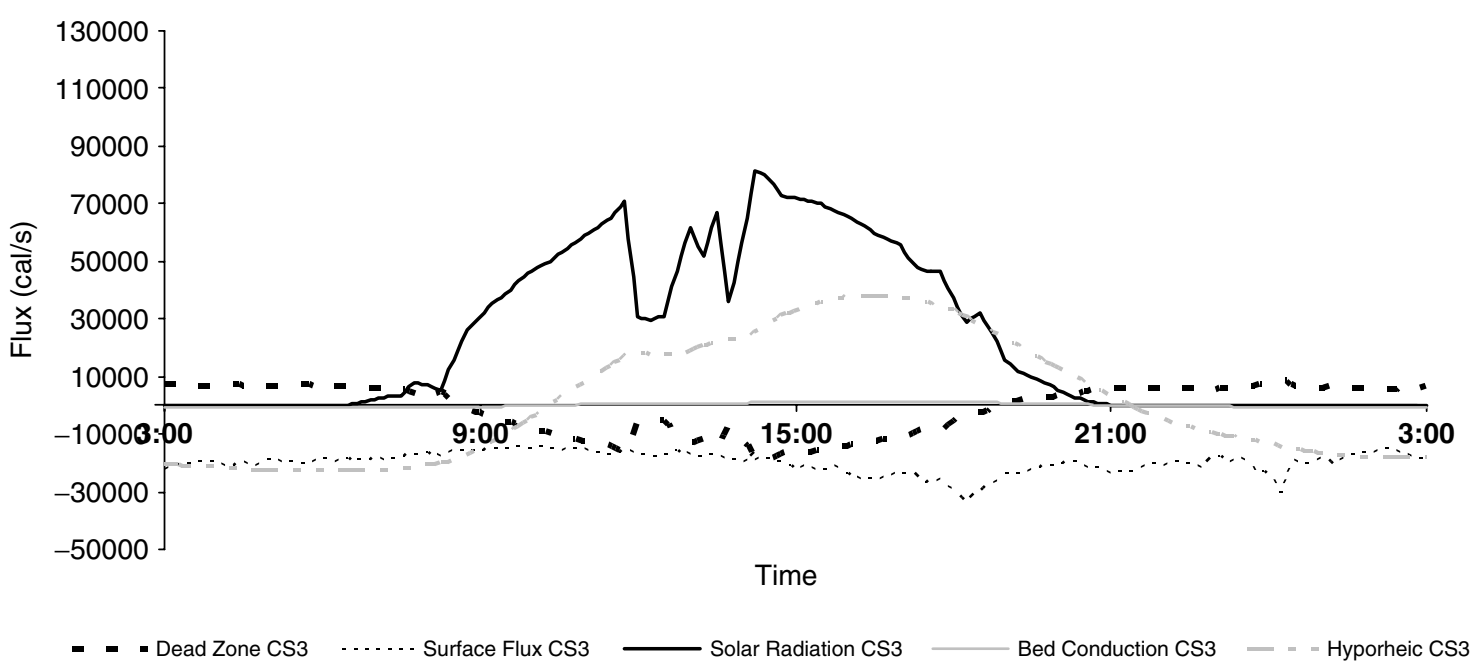

Figure 14. Heat balance at cross-section 3 over one day ( 3 a.m.-3 a.m.) in the main channel of the river

confirm that the hyporheic heat flux affects temperature behaviour in this system. During the night and early morning, the hyporheic zone acts as a heat sink. During the mid-morning and into the late evening, it acts as a heat source and contributes to the time lag in observed in-stream temperature fluctuations.

Table II shows the overall effects of each flux over a day. Similar to what was shown in Figures 13 and 14, Table II demonstrates that the shortwave solar radiation is the largest heat flux into the river over a day.

Table II. Percentage of each flux over a day (3 a.m.-3 a.m.) where negative values represent a heat loss from the main channel and positive values are a heat gain

\begin{tabular}{lcc}
\hline & CS 2 (\%) & CS 3 (\%) \\
\hline Dead zone flux & -3 & -3 \\
Surface fluxes & -42 & -44 \\
Shortwave solar radiation flux & 49 & 50 \\
Bed conduction flux & 1 & 0 \\
Hyporheic flux & 5 & 3 \\
\hline
\end{tabular}

Note: CS, cross-section.
Additionally, it illustrates that there is a net heat loss (3\% of the total) into the dead zones. Although the effect of bed conduction is minimal, the hyporheic flux is a fairly significant portion of the heat balance (3-5\%). The most interesting observation from Table II is that the dead zone, bed conduction and hyporheic fluxes nearly cancel each other out. Over a day, one could account for these fluxes and the average daily temperature would not be affected. These fluxes do, however, change the amplitude and time lag associated with in-stream diurnal fluctuations, improve the ability to predict instream temperatures accurately and assist in determining optimal management strategies to reduce maximum daily temperatures.

\section{CONCLUSIONS}

A data collection system was designed to determine the significance of energy fluxes for inclusion in a temperature model of the Virgin River. These data were effective in identifying the important energy fluxes in the system, and modelling results lent credibility about the 
dominant fluxes that should be quantified to understand in-stream temperature diurnal variations more accurately.

It was found that bed conduction in the system can be important due to the interaction of the bed with the water column. In sections of river where hyporheic flow is significant, there is a need to isolate temperature responses due to conduction and advection through the hyporheic zone. Independent measures of these fluxes were useful in model development, parameterization and testing. The use of temperature probes placed both within and outside a cylinder can be an effective method to separate the two influences if placed in a neutral section of the stream (no strong upwelling or downwelling).

Hyporheic flow was identified as an important buffering mechanism for in-stream temperatures in the Virgin River. It plays a more significant role in the lower portion of the river (CS 2 and 3) where unconsolidated sediments seem to promote hyporheic exchange. Temperatures in the dead zones tend to track closely with those in the main channel except during warming of the exposed dead zone at CS 3 during the hottest portion of the summer. Many of the dead zones were shown to be slightly cooler than the main channel during the middle of the day, and the modelling results suggest that although temperatures are similar to those in the main channel, dead zones provide a heat sink during the day.

The pyranometer measurements show that only a small fraction of shortwave radiation is reflected off the water surface. Shortwave radiation does penetrate to the bottom of the channel, however, the effects of these fluxes appear to be muted by competing influences of advection over the surface, conduction with the water column and deeper alluvium and hyporheic exchange.

Overall, the data collection approach was successful at providing semi-quantitative information about the key heat sources and sinks. Additionally, the data provided critical information for model development, testing, calibration and corroboration.

\section{ACKNOWLEDGEMENTS}

We would like to acknowledge the Graduate Assistance for Areas of National Need (GAANN) fellowship that funded this research. We are indebted to our field crews (Quin Bingham, Andrew Neilson, Amber Spackman, Kiran Chinnayakanahalli, Tenielle Beckstead and Jeremy Butterbaugh), Steve Meismer at the Washington County Water Conservancy District, Rick Fridell and Amos Rehm at the Utah Division of Wildlife Resources and Mark Winkelaar at the Utah Water Research Laboratory for their support of this research.

\section{REFERENCES}

Addley C, Neilson BT, Basdekas L, Hardy T. 2005. Virgin River Temperature Model Validation, Utah Water Research Laboratory, Utah State University, 19

Alexander MD, Caissie D. 2003. Variability and comparison of hyporheic water temperatures and seepage fluxes in a small atlantic salmon stream. Ground Water 41: 72-82.
Arrigoni AS, Poole G, Mertes LAK, O'daniel SJ, Woessner W, Thomas SA. 2008. Buffered, lagged, or cooled? Disentangling hyporheic influences on temperature cycles in stream channels. Water Resources Research 44: W09418. DOI: 10.1029/2007WR006480.

Austin RW, Halikas G. 1976. The Index of Refraction of Seawater, University of California, San Diego Visibility Laboratory of the Scripps Institution of Oceanography, 121.

Bencala KE, Walters RA. 1983. Simulation of solute transport in a mountain pool-and-riffle stream: a transient storage model. Water Resources Research 19: 718-724.

Beschta RL, Weatherred J. 1984. TEMP-84. A computer model for predicting stream temperatures resulting from the management of streamside vegetation. United States Department of Agriculture-United States Forest Service, WSDG-AD-00009. Fort Collins, CO

Beschta RL, Weatherred J. 1987. TEMP-86. Users Guide Department of Engineering, Oregon State University.

Boyd M, Kasper B. 2003. Analytical methods for dynamic open channel heat and mass transfer, methodology for the Heat Source Model version 7.0. Carollo Engineers.

Brown GW. 1970. Predicting the effect of clearcutting on stream temperature. Journal of Soil and Water Conservation 25: 11-13.

Cardenas MB, Wilson JL. 2007. Effects of current-bed from induced fluid flow on the thermal regime of sediments. Water Resources Research 43: W08431. DOI: 10.1029/2006WR005343.

Chapra SC. 1997. Surface Water Quality Modeling. McGraw-Hill: New York.

Constantz J, Stewart AE, Niswonger R, Sarma L. 2002. Analysis of temperature profiles for investigating stream losses beneath ephemeral channels. Water Resources Research 38(12): 1316. DOI 10.1029/2001WR001221.

Curry RA, Noakes DLG. 1995. Groundwater and the selection of spawning sites by brook trout (Salvelinus fontinalis). Canadian Journal of Fisheries and Aquatic Sciences 52: 1733-1740.

Curry RA, Noakes DLG, Morgan GE. 1995. Groundwater and the incubation and emergence of brook trout (Salvelinus fontinalis). Canadian Journal of Fisheries and Aquatic Sciences 52: 1741-1749.

Dale HM, Gillespie T. 1977. Diurnal fluctuations of temperature near the bottom of shallow water bodies as affected by solar radiation, bottom color and water circulation. Hydrobiologia 55: 87.

Evans EC, Mcgregor GR, Petts GE. 1998. River energy budgets with special reference to river bed processes. Hydrological Processes 12 575-595.

Evans EC, Petts GE. 1997. Hyporheic temperature patterns within riffles. Hydrological Sciences 42(2): 199-214.

Gooseff MN, Mcglynn BL. 2005. A stream tracer technique employing ionic tracers and specific conductance data applied to the Maimai Catchment, New Zealand. Hydrological Processes 19: 2491-2506.

Hatch CE, Fisher AT, Revenaugh JS, Constantz J, Ruehl C. 2006. Quantifying surface water-groundwater interactions using time series analysis of streambed thermal records: methods development. Water Resources Research 42: DOI: 10.1029/2005WR004787.

Hauser GE, Schohl GA. 2003. River Modeling System v.4-User Guide and Technical Reference. TVA River System Operations and Environment. Norris, Tennessee.

Herbert LR. 1995. Seepage Study of the Virgin River from Ash Creek to Harrisburg Dome, Washington County, Utah. United States Geologica Survey/State of Utah Department of Natural Resources: Salt Lake City, Utah; 8.

Hondzo M, Stefan HG. 1994. Riverbed heat conduction prediction. Water Resources Research 30: 1503-1513.

Jerlov NG. 1976. Marine Optics, 2nd edn. Elsevier Scientific Publishing Company: Amsterdam, New York.

Jobson HE. 1977. Bed conduction computation for thermal models. Journal of the Hyrdaulics Division, ASCE 103: 1213-1216.

Johnson SL. 2004. Factors influencing stream temperature in small streams: substrate effects and a shading experiment. Canadian Journal of Fisheries and Aquatic Sciences 61: 913-923.

Kirk JTO. 1994. Light and Photosynthesis in Aquatic Ecosystems, 2nd edn. Cambridge University Press: New York.

Loheide SP, Gorelick SM. 2006. Quantifying stream-aquifer interactions through the analysis of remotely sensed thermographic profiles in in situ temperature histories. Environmental Science and Technology 40: $3336-3341$.

Lu N, Ge S. 1996. Effect of horizontal heat and fluid flow on the vertical temperature distribution in a semiconfining layer. Water Resources Research 32: 1449-1453.

Meier W, Bonjour C, Wuest A, Reichert P. 2003. Modeling the effect of water diversion on the temperature of mountain streams. Journal of Environmental Engineering 129: 755-764. 
Neilson BT. 2006. Dynamic stream temperature modeling: understanding the causes and effects of temperature impairments and uncertainty in predictions. Dissertation, Utah State University.

Runkel RL. 1998. One dimensional transport with inflow and storage (OTIS): a solute transport model for streams and rivers, U.S. Geological Survey Water-Resources Investigation Report 98-4018. U.S. Geological Survey: Denver; 73.

Rutherford JC, Blackett S, Blackett C, Saito L, Davies-Colley RJ. 1997. Predicting the effects of shade on water temperature in small streams. New Zealand Journal of Marine and Freshwater Research. The Royal Society of New Zealand 31(5): 707-721.

Sellers WD. 1965. Physical Climatology, 2nd edn. University of Chicago Press: Chicago.

Silliman SE, Booth DF. 1993. Analysis of time-series measurements of sediment temperature for identification of gaining vs. losing portions of Juday Creek, Indiana. Journal of Hydrology 146: 131-148.

Silliman SE, Ramirez J, Mccabe RL. 1995. Quantifying downflow through creek sediments using temperature time series: onedimensional solution incorporating measured surface temperature. Journal of Hydrology 167: 99-119.

Sinokrot BA, Stefan HG. 1993. Stream temperature dynamics: measurements and modeling. Water Resources Research 29: 2299-2312.

Stonestrom DA, Constantz J. 2003. Heat as a Tool for Studying the Movement of Ground Water Near Streams, US Geological Survey Circular 1260. US Geological Survey: Denver, CO.

Stream Solute Workshop. 1990. Concepts and methods for assessing solute dynamics in stream ecosystems. Journal of the North American Benthological Society 9: 95-119.
Sullivan K, Tooley J, Doughty K, Caldwell J, Knudsen P. 1990. Evaluation of prediction models and characterization of stream temperature regimes in Washington. Timber/Fish/Wildlife Report No. TFW-WQ3-90-006. Washington Department of Natural Resources: Olympia, WA.

Sweeny C, Gnanadesikan A, Griffies SM, Harrison MJ, Rosati AJ, Samuels BL. 2005. Impacts of shortwave penetration depth on largescale ocean circulation and heat transport. Journal of Physical Oceanography 35: 1103-1119.

Theurer FD, Voos KA, Miller WJ. 1984. Instream water temperature model. US Fish and Wildlife Service.

Vrugt JA, Gupta HV, Bastidas LA, Bouten W, Sorooshian S. 2003. Effective and efficient algorithm for multiobjective optimization of hydrologic models. Water Resources Research 39(8): 1214.

Wang J, Seyed-Yagoobi J. 1994. Effects of water turbidity and salt concentration levels on penetration of solar radiation under water. Solar Energy 52: 429-438.

Webb BW, Zhang Y. 1997. Spatial and seasonal variability in the components of the river heat budget. Hydrological Processes 11: 79-101.

White DS, Elzinga CH, Hendricks SP. 1987. Temperature patterns within the hyporheic zone of a northern Michigan river. Journal of the North American Benthological Society 6: 85-91. 